\title{
Study on Extraction of Porphyra Polysaccahride and Its Antioxidant Properties
}

\author{
Ying Pan ${ }^{1, a}$, Ying Meng ${ }^{2, b^{*}}$, Yan Geng ${ }^{2, c}$, Bin Zhang ${ }^{1, d}$ and Tengfei Lei ${ }^{1, e}$ \\ ${ }^{1}$ College of Textiles and Clothing, Qingdao University, Qingdao 266071, Shandong, China \\ ${ }^{2}$ School of Zaozhuang University, Zaozhuang 277100, Shandong, China \\ azzxy_michiyo@163.com, b798478721@qq.com
}

*The corresponding author

Keyword: Porphyra polysaccharide; Single factor; Orthogonal test; Antioxidant property; IR

\begin{abstract}
On the base of single factor including extraction temperature, extraction time and the ratio of raw materials to water, experiments the research aims to explore the suitable consideration considering the optimal conditions of extracting porphyra polysaccharide. According to the experiments, the optimal conditions for extracting porphyra polysaccharide can be as follows: extraction temperature $80{ }^{\circ} \mathrm{C}$, extraction time $2 \mathrm{~h}$, the ratio of raw materials to water was 1: 20 . Following this, the yield of porphyra polysaccharide could be $3 \%$. On the next stage, Sevag has been employed to remove the obtained protein. After six times, the content of protein can be reduced from $14.31 \%$ to $6.0 \%$ whilst the content of porphyra polysaccharide can reach $87.66 \%$. The result of antioxidant activity revealed that the extract showed good scavenging effect for $\cdot \mathrm{OH}$ and DPPH. Besides, there were obvious positive relationship between the concentration and activity of the extract. When the concentration of porphyra polysaccharide was $3 \mathrm{mg} / \mathrm{mL}, \cdot \mathrm{OH}$ scavenging rate can reach $90.9 \%$; and when the concentration of porphyra polysaccharide was 2.5 $\mathrm{mg} / \mathrm{mL}, \mathrm{DPPH} \cdot$ scavenging rate can reach $90 \%$.
\end{abstract}

\section{Introduction}

Polysaccharides are a natural polymer compound which can be founded in plants, animals and microorganisms, consisting of monosaccharides. According to different sources, polysaccharides can be divided into animal polysaccharides, plant polysaccharides and microbial polysaccharides[1]. In recent years, with the various functions of polysaccharides, such as anti-tumor, anti-cancer and other studies began to be found, the study of polysaccharides has also been more and more frequent. At present, the research of marine functional polysaccharides attracts people's attention. Laver is a kind of food which is very popular. Porphyra polysaccharide mainly divided into two categories: seaweed glue and agar, and the main difference between the two categories lies in the sulfate content. Due to the growth conditions, growth environment and other factors, the content of Porphyra polysaccharide will have a certain degree of difference[2]. The monosaccharide composition in each polysaccharide component also varies. Research shows that Porphyra polysaccharide mainly composed of fucose, galactose, mannose, glucose and xylose, which is acidic heteropolysaccharide a higher content of uronic acid[3]. Experimental study on biological activity of Porphyra polysaccharide showed that it has a variety of biological activity and medicinal value, such as hypolipidemic, hypoglycemic, anti-inflammatory, anti thrombosis, anti fatigue, enhance immunity, inhibit tumor growth[4]. Therefore, it has broad prospects for development in health care products and medicine.

In this paper, the extraction conditions were optimized on the basis of single factor experiment, in order to maximize the yield of Porphyra polysaccharide. At the same time, the antioxidant activity in vitro of Polysaccharide from Porphyra yezoensis was studied. 


\section{Materials and Methods}

Materials and Instruments. Porphyra tenera : Purchased in Zaozhuang Xinhua wholesale market. HH-2 digital display thermostatic bath:Jiangsu Jintan Yitong Electronics Co. , Ltd. ; SHZ-D (III) Circulating water vacuum pump;Freeze dryer;DHG-9070A DHG Series Heating and Drying Oven; B3200S-T Ultrasonic machine: Sino Pacific ultrasonic Co. , Ltd; T6 UV-Vis spectrophotometer: Beijing Puxi Instrument Equipment Co. , Ltd department; RE-52AA Rotary evaporator: Shanghai biochemical instrument factory; JY3001Electronic balance: Shanghai equitable Instrument Factory.

Acetone, Anhydrous ethanol, Ether, N-butyl alcohol, Chloroform, Concentrated sulfuric acid, Phen, Phosphori, Bovine serum protein, Coomassie brilliant blue G250.

Methods. Pretreatment of raw materials

Dried Porphyra tenera is dried at 60 degrees and then crushed through 80 mesh sieve. Then refluxing with absolute alcohol for $2 \mathrm{~h}$ to remove small molecule pigments and esters . Then dried with absolute alcohol, acetone and petroleum ether and dried to obtain laver power.

Method for extracting polysaccharide from Porphyra tenera

A certain quantity of laver powder is determined, add distilled water to a certain proportion, then heat it in water -bath. After cooling, rotating evaporation to a certain volume. Stand for twelve hours, centrifugate and freeze drying it, finally porphyra polysaccharides were obtained.

Effect of Different Extraction Conditions on the Yield of Porphyra Polysaccharide. Effect of different temperature on the yield of porphyra polysaccharide.

According to the method shown in 1. 1. 2, $5 \mathrm{~g}$ laver powder was determined, respectively. The solid-liquid ratio is $1: 20(\mathrm{~g} / \mathrm{mL})$, at $65,70,75,80,85,90{ }^{\circ} \mathrm{C}$ conditions. Extracting it $2 \mathrm{~h}$, Measured the effect of temperature on extraction rate of porphyra polysaccharide.

Effect of different solid-liquid ratio on the yield of porphyra polysaccharide.

$5 \mathrm{~g}$ laver powder was determined, respectively. Temperature is kept constant at $80^{\circ} \mathrm{C}$, the solid-liquid ratio is respectively 1:5, 1:10, 1:20, 1:30, 1:40. Extracting it2h, Measured the effect of different solid-liquid ratio on extraction rate of porphyra polysaccharide.

Effect of different extraction time on the yield of porphyra polysaccharide

$5 \mathrm{~g}$ laver powder was determined, respectively. Solid-liquid ratio is kept constant at 1:20 $(\mathrm{g} / \mathrm{mL})$ and temperature is kept constant at $80{ }^{\circ} \mathrm{C}$, the extracting time is respectively $1,1.5,2,2.5,3 \mathrm{~h}$. Measured the effect of different time on extraction rate of porphyra polysaccharide.

The Determination Method of Porphyra Polysaccharide. Determining polysaccharide content and purity by the phenol-sulfuric acid method, Glucose was used as the standard sample.

yield of porphyra polysaccharide $1 \%=\frac{\text { quality of porphyra polysaccharides }}{\text { quality of raw mate }} \times 100$

Protein Removal. Sevag method for protein removal. Determining protein content by Coomassie brilliant biue method.

Optimization of Extraction Conditions of Porphyra Polisaccharide by Orthogonal Test. On the basis of single factor experiment, the orthogonal experiment design was used to optimize the factors affecting the extraction of laver polysaccharide. The level of factor is shown in table 1.

Table 1 Factors and Levels of orthogonal experiment methodology

\begin{tabular}{|c|c|c|c|}
\hline \multirow{2}{*}{ level } & \multicolumn{3}{|c|}{ factors } \\
\hline & A extraction time/h & B solid-liquid ratio/(g/ml) & $\mathrm{C}$ extraction temperature $/{ }^{\circ} \mathrm{C}$ \\
\hline 1 & 1.5 & $1: 10$ & 75 \\
\hline 2 & 2 & $1: 20$ & 80 \\
\hline 3 & 2. 5 & $1: 30$ & 85 \\
\hline
\end{tabular}

Determination of Porphyra Polysaccharides by Infrared Spectroscopy Dried laver polysaccharide $1 \mathrm{mg} 2 \mathrm{mg}$ was prepared into powder and mixed with $\mathrm{KBr}$. The samples were scanned in $400 \mathrm{~cm}-1 \sim 4000 \mathrm{~cm}-1$ by infrared spectrometer. 
Study on Antioxidant Activity of Porphyra Polysaccharides in Vitro. Determination of reducing power

In the experiment, $\mathrm{V}$ ( $\mathrm{C}$ ascorbic acid) was used as the control sample, and the polysaccharide solution with different mass concentration was used as the experimental group. During the experiment, the sample solution was $1 \mathrm{~mL}$, adding $2.5 \mathrm{~mL}$ phosphate buffer $(\mathrm{pH}=6.6)$, and then evenly mixed with $2.5 \mathrm{~mL} 1 \%$ potassium ferricyanide solution, mixed evenly, and then heated by $50 \mathrm{~min}$ at constant temperature of 20 . When the solution is cooled to room temperature, $2.5 \mathrm{~mL}$ $10 \%$ of three chloroacetic acid solution is added. After centrifugation, $2.5 \mathrm{~mL}$ of supernatant was added, and $2.5 \mathrm{~mL}$ distilled water and $0.5 \mathrm{~mL} 0.1 \% \mathrm{FeCl} 3$ solution were added. The absorbance was measured at $700 \mathrm{~nm}$. The higher the absorbance was, the stronger the reducibility of the reaction mixture was.

Determination of the scavenging capacity of Porphyra polysaccharise on $\cdot \mathrm{OH}$.

The experiment was carried out with different temperature and concentration of polysaccharide solution as experimental group, and VC as control group. In the course of the experiment to $1 \mathrm{~mL}$ in the sample solution with $6 \mathrm{mmol} / \mathrm{L} \mathrm{FeSO} 41 \mathrm{~mL}$ solution, $\mathrm{H} 2 \mathrm{O} 2$ solution after fully mixed with 1 $\mathrm{mL}$ concentration of $6 \mathrm{mmol} / \mathrm{L}$, standing for $10 \mathrm{~min}$. After adding $6 \mathrm{mmol} / \mathrm{L}$ salicylic acid solution $1 \mathrm{~mL}$, reaction in 37 water bath for $30 \mathrm{~min}$, the reaction was completed at $3000 \mathrm{r} / \mathrm{min}$ and centrifuged at room temperature for $10 \mathrm{~min}$. The final supernatant at $510 \mathrm{~nm}$ wavelength to measure its absorbance of blank control with double distilled water instead of polysaccharide solution.

$$
\mathrm{SE} / \%=\left(1-\frac{\mathrm{Ai}-\mathrm{Aj}}{\mathrm{A} 0}\right) \times 100
$$

Type: SE represents clearance, $\mathrm{Ai}$ is the absorbance of the sample solution, Aj is the absorbance of the sample solution of double distilled water instead of salicylic acid, A0 control group absorbance.

Determination of free radical activity of DPPH

According to the method of AMAROWICZ

$$
\mathrm{SE} / \%=\left(1-\frac{\mathrm{Ai}-\mathrm{Aj}}{\mathrm{A} 0}\right) \times 100
$$

Type: SE represents clearance, $\mathrm{Ai}$ is the absorbance of $2 \mathrm{~mL} \mathrm{DPPH}+2 \mathrm{~mL}$ solution sample solution absorbance, $\mathrm{Aj}$ is the absorbance of $2 \mathrm{ml}$ absolute ethyl alcohol $+2 \mathrm{~mL}$ solution sample solution A0 is the absorbance of $2 \mathrm{ml} \mathrm{DPPH}+2 \mathrm{ml} \mathrm{DDW}$.

Statistical Analysis. Using Origin 8 mapping, Design Expert 7. 5 for data processing.

\section{Result}

The Effect of Extraction Temperature on the Yield of of Porphyra Polysaccharide. As shown in Fig. 1

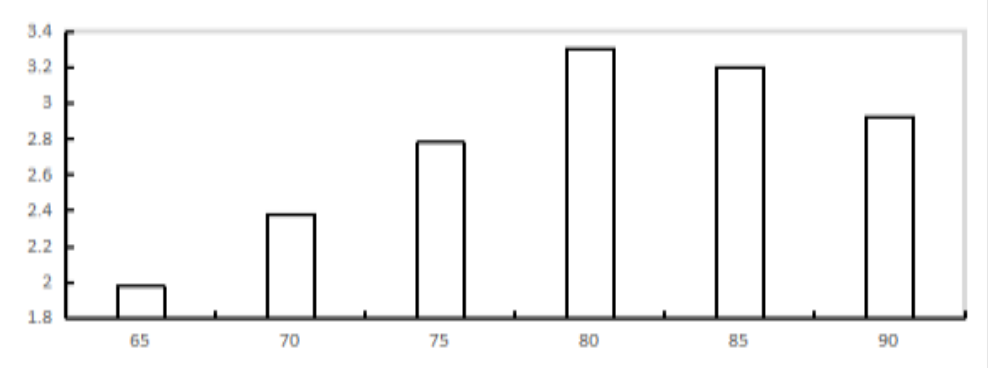

Figure 1. The effect of extraction temperature on the yield of of Porphyra Polysaccharid 
According to Fig. 1, the extraction yield of laver polysaccharide increased first and then decreased with the increase of temperature. When the extraction temperature was 80degrees Celsius, the yield was the highest. This may be because the extraction of polysaccharides is a continuous dissolution process, high temperature is in favor of cell disruption, the polysaccharide solubility, the yield increased; but when the temperature is too high, the high temperature will destroy the continuous extraction of polysaccharide structure, polysaccharide degradation rate decreased. And in actual production work, too high temperature will increase energy consumption and equipment investment[5] After considering the experimental cost and other factors. The optimum extraction temperature of laver polysaccharide was determined at 80degrees Celsius .

The Effect of the Ratio of Raw Materials to Water on the Yield of Porphyra Polysaccharide

From Fig. 2 we can see, with the solid-liquid ratio increased, the yield of polysaccharide will be increased; and when the solid-liquid ratio is too high, the rate did not increase but decrease much sugar, probably because of the polysaccharide miscibility with water in any ratio, the more water, the subsequent process of the extract the cost of alcohol concentration and alcohol dosage the more concentration of extraction of polysaccharide is too low, the same concentration of alcohol will be more difficult to precipitate polysaccharides. Therefore, in this experiment, the best ratio of material to solution is chosen at 1: 20 .

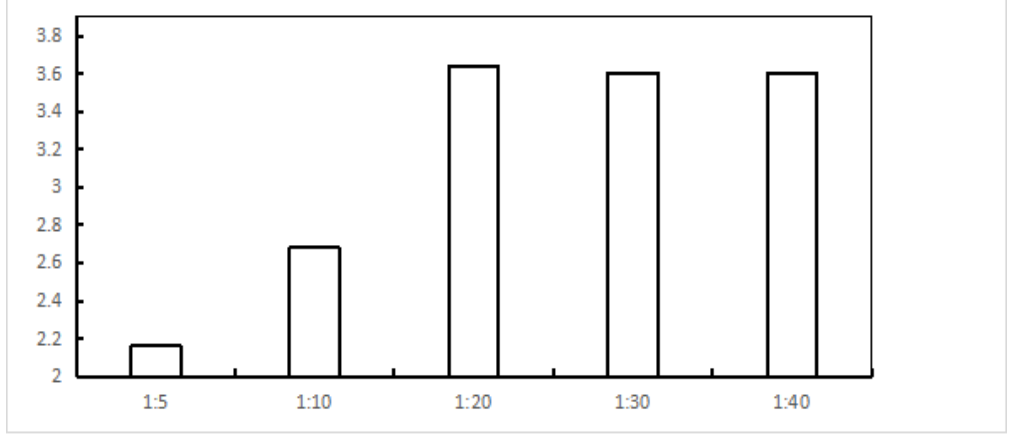

Figure 2. The effect of the ratio of raw materials to water on the yield of Porphyra Polysaccharide

The Effect of Extraction Time on the Yield of Porphyra Polysaccharide. From Fig. 3, the extraction time is too short, not conducive to the crushing of plant cells, polysaccharide was not fully dissolved, thereby reducing the polysaccharide extraction rate of [6]; the extraction time is too long, may cause the degradation or destruction of some polysaccharides in high temperature extraction process, reduce the rate of polysaccharides, and freezing after drying the crude polysaccharide darker, affect the determination of dissolved absorbance and later, resulting in a waste of resources, and increase the cost of unnecessary energy consumption. Therefore, in this experiment, considering the cost and efficiency factors, $2 \mathrm{~h}$ is the best extraction time. Under this condition, the yield of Porphyra polysaccharide is 3. $89 \%$.

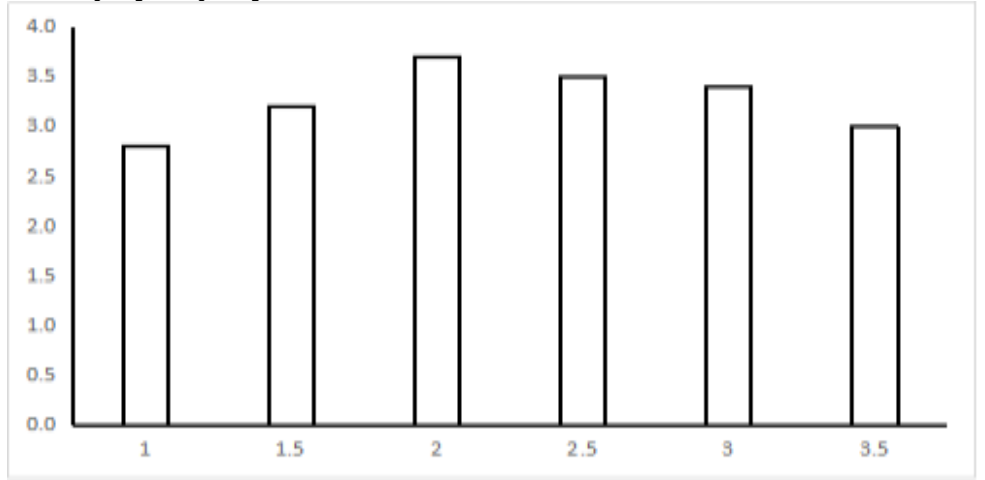

Figure 3. The effect of extraction time on the yield of Porphyra Polysaccharide 
Results of the Orthogonal Test. The results of orthogonal test showed that the effect of 3 factors on the extraction rate of final polysaccharide was the extraction temperature $>$ solid-liquid ratio > extraction time, and the effect of solid-liquid ratio on the yield of polysaccharide was the most significant. The results showed that the 2 factors had the greatest influence on the final polysaccharide extraction rate. At the same time, the orthogonal experiment showed that the optimum extraction conditions were $\mathrm{A} 3 \mathrm{~B} 2 \mathrm{C} 2$, that is, the extraction time was $2 \mathrm{~h}$, the ratio of material to liquid was 1 to $20(\mathrm{~g} / \mathrm{mL})$, and the extraction temperature was 80 . Under this condition, the final yield of crude polysaccharide could reach 3. 8910\%[7].

Table 2 Results of the orthogonal test

\begin{tabular}{|c|c|c|c|c|}
\hline \multirow{2}{*}{ number } & \multicolumn{3}{|c|}{ factors } & \multirow{2}{*}{$\begin{array}{c}\text { the yield of Porphyra } \\
\text { Polysaccharide/ } \%\end{array}$} \\
\hline & A & B & $\mathrm{C}$ & \\
\hline 1 & 1 & 1 & 1 & 2. 9412 \\
\hline 2 & 1 & 2 & 2 & 3. 9910 \\
\hline 3 & 1 & 3 & 3 & 2. 7700 \\
\hline 4 & 2 & 1 & 2 & 3. 1514 \\
\hline 5 & 2 & 2 & 3 & 3. 3199 \\
\hline 6 & 2 & 3 & 1 & 2. 8556 \\
\hline 7 & 3 & 1 & 3 & 2. 9856 \\
\hline 8 & 3 & 2 & 1 & 3. 2808 \\
\hline 9 & 3 & 3 & 2 & 3. 4846 \\
\hline I & 3. 001 & 2. 826 & 2. 826 & - \\
\hline II & 2. 909 & 3. 297 & 3. 309 & - \\
\hline III & 3.05 & 2. 837 & 2. 825 & _ \\
\hline range & 0.141 & 0.417 & 0.484 & - \\
\hline
\end{tabular}

Replication Experiment. In the course of the experiment, we carried out a confirmatory experiment based on the experimental results obtained from the orthogonal experiment, in order to investigate the reproducibility of the better experimental conditions. Accurately weighed $5 \mathrm{~g}$ laver powder, adding distilled water according to the ratio of $100 \mathrm{~mL}, 80 \mathrm{DEG} \mathrm{C}$ water bath extraction $120 \mathrm{~min}$, which dissolved polysaccharide, cooling after centrifugation, the supernatant was collected, to volume $100 \mathrm{~mL}$, Using the coloration by phenol sulfuric acid method, measured the absorbance, and calculate the polysaccharide content and yield, results showed that Porphyra polysaccharide the rate can reach 3.95\%[8] . It can be proved that the yield of Porphyra polysaccharide is the highest under these conditions.

Determination of Protein Removal Times by Sevag Method. During the experiment, accurately weighed amount of seaweed polysaccharide amount dissolved in ultrapure water, adding Sevag reagent according to the volume of the sample solution 1/3 1/4, stirring in the centrifuge 15 min, speed of 6500r, after using a separatory funnel lower organic reagent and protein denaturation of the intermediate layer is removed, the operation is repeated 6 times, after the supernatant was collected, concentrated after freeze drying, can be obtained from the polysaccharide has protein removal[9]. The results are shown in table 3.

Table 3 The content of protein by Sevag reagent

\begin{tabular}{|c|c|c|c|c|}
\hline name & quality/g & $\begin{array}{c}\text { absorbance } \\
\text { (average } \\
\text { value })\end{array}$ & protein content/\% & polysaccharide content $/ \%$ \\
\hline before & $0.100 \mathrm{~g}$ & 0.704 & 14.1301 & 78.0317 \\
\hline after & $0.0112 \mathrm{~g}$ & 0.690 & 6.0880 & 87.6601 \\
\hline
\end{tabular}


Inf rared Spectrums Results of Porphyra Polysaccharise. From the infrared spectra of crude polysaccharide extracted, we can see that the characteristic structure of the general polysaccharide in the infrared spectrum, the peak width has the following characteristic peak of :3 $442 \mathrm{~cm}-1$ is the polysaccharides $-\mathrm{OH}$ stretching vibration peak; 2950 is the stretching vibration peak of $\mathrm{C}-\mathrm{H}$, according to this judgment this kind of compound carbohydrate compounds. $1255 \mathrm{~cm}-1$ suggests that it may exist sulfate; at $1688 \mathrm{~cm}-1$ peak showed the existence of $\mathrm{C}=\mathrm{O}$ bonds, It is proved that there may be a protein bound to the polysaccharide.

Antioxidant Activity of Porphyra Polysaccharise in Vitro. Determination of reducing power

The reducing capacity of Porphyra polysaccharide has a good dose effect relationship, and it will increase with the increase of mass concentration. When the concentration is $4 \mathrm{mg} / \mathrm{mL}$, the absorbance is 0.69 , which proves that it has a certain reducing power. However, its reducing power is weaker than that of VC. This may be because the extracted Porphyra polysaccharide has a relatively less reductive end of [10] [13]

Determination of the scavenging capacity of Porphyra polysaccharise on $\cdot \mathrm{OH}$

Porphyra polysaccharide's scavenging ability on $\mathrm{OH}$ changed with the concentration. When the concentration was $3 \mathrm{mg} / \mathrm{mL}$, the absorbance can reach $90.9 \%$, with the same concentration of VC is close to. In addition, the scavenging and $\mathrm{OH}$ capacity of the extracted polysaccharides was lower than that of VC. This is probably because $\mathrm{OH}$ must be combined with a hydrogen atom polysaccharide hydrocarbon chain can be cleared, and $\mathrm{VC}$ with strong reducibility, not only can remove $\mathrm{OH}$, even can inhibit $\mathrm{OH}$. [14] [17]

Determination of the scavenging capacity of Porphyra polysaccharise against $\cdot$ DPPH

Porphyra polysaccharide has a significant dose effect relationship on the removal of DPPH. With the increasing concentration of Porphyra, its scavenging ability to DPPH is also increasing. When the mass concentration reached $2.5 \mathrm{mg} / \mathrm{mL}$, and even close to $\mathrm{VC}$, reached $90 \%$.

\section{Conclusion}

The optimum extraction method of Polysaccharide from Porphyra yezoensis was studied. The single factor experiments were carried out on the main factors affecting the extraction rate. On the basis of single factor experiment by orthogonal design of the extraction process is optimized, the optimization results show that the best extraction temperature is $80 \mathrm{DEG} \mathrm{C}$, solid-liquid ratio is 1 : 20 , the extraction time is $2 \mathrm{~h}$. Under these conditions, the yield was the highest, reaching $3 \%$.

Sevag method was used to remove protein during the experiment. The protein content in polysaccharide was lowest and polysaccharide content was the highest when the protein was removed 6 times, respectively, $6 \%$ and $87 \%$ respectively.

It can be seen from the experimental results that Porphyra polysaccharide has strong antioxidant activity in vitro, and has a certain relationship with its mass concentratio

\section{Reference}

[1] Wu Q, Tan Z, Liu H, et al. Chemical characterization of Auricularia auricula polysaccharides and its pharmacological effect on heart antioxidant enzyme activities and left ventricular function in aged mice[J]. International journal of biological macromolecules, 2010, 46(3): 284-288

[2] Huang Q, Jin Y, Zhang L, et al. Structure, molecular size and antitumor activities of polysaccharides from Poria cocos mycelia produced in fermenter[J]. Carbohydrate Polymers, 2007, 70(3): 324-333

[3] Yang X, Zhao Y, Li G, et al. Chemical composition and immuno -stimulating properties of polysaccharide biological response modifier isolated from Radix Angelica sinensis[J]. Food chemistry, 2008, 106(1): 269-276

[4] Zhu C, Liu X. Optimization of extraction process of crude polysaccha - rides from Pomegranate peel by response surface methodology [J]. Carbohydrate polymers, 2013, 92(2): 1197-1202 
[5] Amarowicz R, Naczk M, Shahidi F. Antioxidant activity of various fractions of non-tannin phenolics of canola hulls[J]. Journal of Agricultural and Food Chemistry, 2000, 48(7): 2755-2759

[6] Zou S, Zhang X, Yao W, et al. Structure characterization and hypo-glycemic activity of a polysaccharide isolated from the fruit of Lyci-um barbarum L[J]. Carbohydrate Polymers, 2010, 80(4): 1161-1167

[7] Smirnoff N, Cumbes Q J. Hydroxyl radical scavenging activity of compatible solutes[J]. Phytochemistry, 1989, 28(4): 1057-1060

[8] Zubia M, Fabre M S, Kerjean V, et al. Antioxidant and cytotoxic activities of some red algae (Rhodophyta) from Brittany coasts (France) [J]. Botanica Marina, 2009, 52(3): 268-277

[9] Ding L, Qin S, Li F S, et al. Isolation, antimicrobial activity, and metabolites of fungus cladosporium sp. associated with red alga Porphyra yezoensis [J]. Current Microbiology, 2008, 56(3): 229-235

[10] Yang Y J, Nam S J, Kong G, et al. A case-control study on seaweed consumption and the risk of breast cancer [J]. British Journal of Nutrition, 2010, 103(9): 1345-1353

[11] Tsuge K, Okabe M, Yoshimura T, et al. Dietary effects of Porphyran from Porphyra yezoensis on growth and lipid metabolism of Sprague-Dawley rats [J]. Food Science and Technology Research, 2004, 10(2): 147-151

[12] Yoshizawa Y, Ametani A, Tsunehiro J, et al. Macrophage stimulation activity of the polysaccharide fraction from a marine alga (Porphyra Yezoensis): structure-function relationships and improved solubility [J]. Bioscience Biotechnology Biochemistry, 1995, 59(10): 1933-1937

[13] Kommann P. Life histories of monostromatic Porphyra species as a basis for taxonomy and classification[ J]. European Journal of Phycology 1994, 29:69- 71.

[14] Kurugi M. Systematics of Porphyra in Japan[A]. Contributionsto the systematics of benthic marine algae of the North Pacific[J]. Kobe: Japanese Society of Phycology, 1972, 167- 191.

[15] Nelson W A, Knight $G$ A. Endosporangia-a new form of reproduction in the genus Porphyra(Bangiales, Rhodophyta)[J]. Bot Mar, 1995, 38(1): 17- 20.

[16] Knight G A, Nelson W A. An evaluation of characters obtained from life history studies for distinguishing New Zealand Porphyra species[J]. J Appl Phycol, 1999, 11:411- 419.

[17] Tang X, Fei X. Development of suspended conchocelis of Porphyra haitanensis[J]. Chin Ocean Limn, 1998, 16(4): 339345. 